\title{
Analysis of thermal and structural responses of a new diagnostic probe to repeated exposure in ASDEX Upgrade tokamak
}

\author{
${ }^{* 1}$ B. Končar, ${ }^{1}$ O. Costa Garrido, ${ }^{1}$ M. Draksler, ${ }^{2}$ A. Herrmann, ${ }^{1}$ J. Kovačič, ${ }^{3}$ C. Ionita, ${ }^{3}$ R. \\ Schrittwieser \\ ${ }^{1}$ Jožef Stefan Institute, Ljubljana, Slovenia \\ ${ }^{2}$ Max-Planck-Institute for Plasma Physics, Garching near Munich, Germany \\ ${ }^{3}$ Institute for Ion Physics and Applied Physics, University of Innsbruck, Austria \\ *Corresponding author: \\ E-mail address: bostjan.koncar@ijs.si
}

\begin{abstract}
Thermal and structural responses of a new diagnostic probe inside the AUG (ASDEX Upgrade) tokamak has been analysed numerically. This new reciprocating probe has been developed as a multi-diagnostic device for measuring several plasma parameters simultaneously. It is constructed as a universal probe that can be used in different tokamaks by applying corresponding adapters. The probe head design has to go through a number of tests (numerical and experimental) before it can be used in the actual tokamak environment, where it has to withstand repeated exposure to energetic particle fluxes in the scrape-off layer plasma. In this respect, the probe's resilience to the heat loads in AUG has been investigated numerically. The performed transient analyses correspond to a typical triple insertion of the probe head into the plasma during a plasma discharge experiment in AUG. Thermal and mechanical responses of the most critical parts of the probe have been analysed. To avoid the potential pollution of the vacuum vessel, thermal resistance and structural integrity of the probe`s protective shroud have been studied in particular. The protective shroud has been constructed specifically for AUG. The simulations have shown that the shroud is able to withstand the expected plasma exposure and provides sufficient protection for the probe diagnostic and structural parts.
\end{abstract}

\section{KEYWORDS}

New diagnostic probe, protective shroud, ASDEX Upgrade, thermal response, structural analysis 


\section{Introduction}

Development of new diagnostic tools for measuring various plasma parameters in the plasma edge region is an essential part of the preparation and exploitation of Medium-Size Tokamaks (MST). Within the EUROfusion project MST2 [1], the development and manufacturing of a new interchangeable probe head with respective adaptors for different European MST devices is carried out. The probe is intended to be used for comparative measurements in the three present European tokamaks: AUG (Axial-Symmetric Divertor EXperiment - Upgrade) [2] at the IPP (Max-PlanckInstitute for Plasma Physics) in Garching, Germany, TCV (Tokamak a Configuration Variable) [3] at the Swiss Plasma Center (SPC) of the EPFL (École Polytechnique Fédérale de Lausanne) in Lausanne, Switzerland and MAST-U (Mega-Ampere Spherical Tokamak - Upgrade) [4] at the CCFE (Culham Centre for Fusion Energy) in Culham, UK.

Comprehensive and accurate investigation of the scrape-off layer (SOL) requires diagnostics, which enables simultaneous measurement of several plasma parameters on the local scale with a high temporal resolution. Therefore, a set of diagnostics consisting of two Cold Langmuir Probes (CLP), one Electron-Emissive Probe (EEP), two Retarding Field Analysers (RFA) and two Magnetic Pickup Coils has been mounted on a single relatively small probe head - called the New Probe Head (NPH). The development of the diagnostics for the NPH is described in [5]. The probe head design, and later the prototype, has to go through a number of tests (numerical and experimental) before it can be used in the real tokamak, where it will have to withstand repeated exposure to the high heat flux in SOL plasma. The probe exposure time varies from tokamak to tokamak, but it is expected to be in the range of 50 to $500 \mathrm{~ms}$. During one plasma discharge, the probe head can be inserted into the plasma several times, with a delay between insertions in the order of a second. Usually, around 10 to 20 discharges can be expected during one experimental session.

In the present study, the thermal behaviour and structural response of the new probe exposed to plasma in AUG are analysed. The performed transient analyses correspond to a typical triple insertion of the probe head into the vacuum vessel during a plasma discharge experiment. The following sections describe the design adjustment of the probe's protective shroud for the use in AUG and a thermal model of the probe with its key parts. Results of the probe thermal response and the mechanical analysis of the shroud cap are discussed separately. One of the main goals of the study is to evaluate the shroud's resistance to the successive heat loads in SOL.

\section{Probe head design}

The new probe includes several diagnostics that enable detection of various plasma parameters simultaneously. The design of NPH is rather complex, as it has to accommodate four different diagnostics within a small space of the probe head [6].

The newly constructed probe head (Figure 1) will be the first one used in a tokamak that incorporates RFAs, EEP and CLPs in one place [5]. This is very useful for correct evaluation of the heat fluxes at the SOL mid-plane. In addition, the EEP should be able to provide direct realtime measurements of the plasma potential. This data is invaluable for improving the understanding of electric fields in SOL, especially during dynamic events. The inclusion of magnetic pick-ups adds another layer that can be used to resolve the transport behaviour during dynamic events, such as Edge Localized Modes (ELMs). Probe diagnostics is discussed in detail in [5]. 


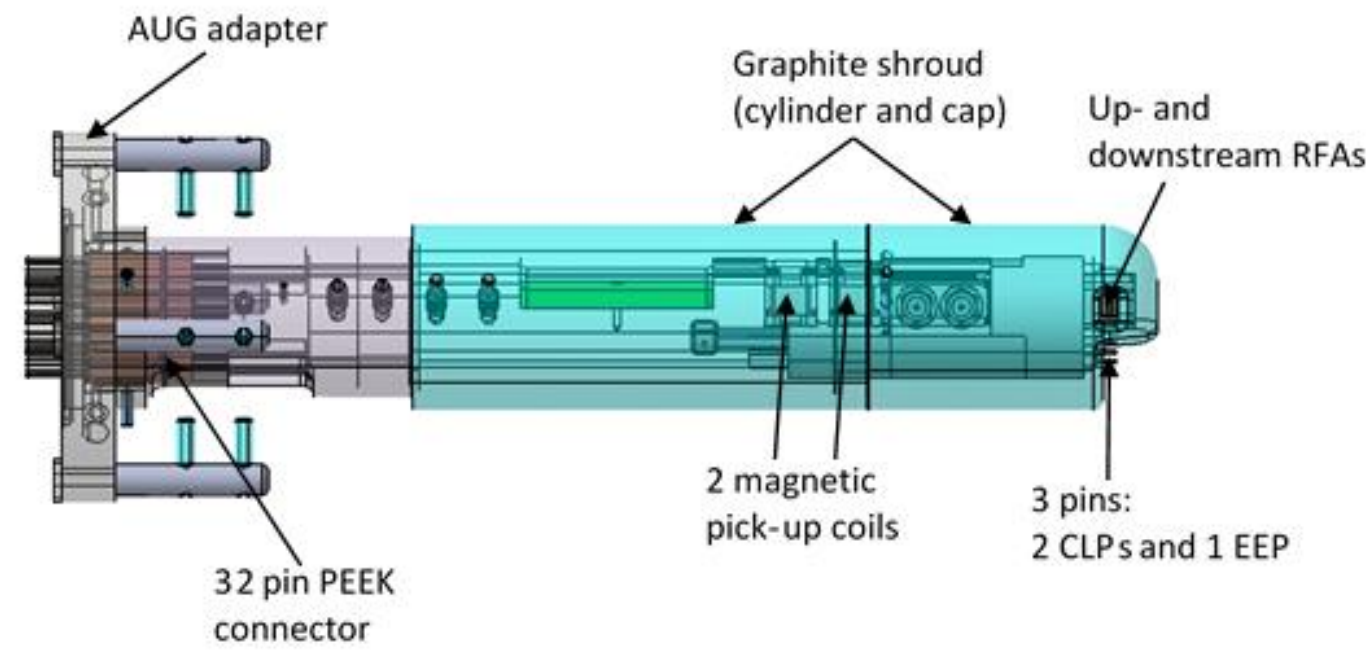

Figure 1: The New Probe Head (NPH) with diagnostics for transport parameter measurements in the SOL of MSTs.

It is required that the probe goes through a number of tests before it can be commissioned for the use in a tokamak. The most important test of the probe is to demonstrate its ability to repeatedly withstand the exposure to the high heat flux in the SOL plasma. It should be noted that in Figure 1 only the diagnostic parts of the probe and graphite shroud are presented. The probe supporting structures below the PEEK connector are not shown, but are included in the thermal model of the probe in Figure 3.

\subsection{Adaptation of the NPH design for measurements in AUG}

The AUG plasma volume is about $13 \mathrm{~m}^{3}$ and can be heated with up to $32 \mathrm{MW}$, typically 5 to $10 \mathrm{MW}$, resulting in a parallel heat flux at the separatrix of about $150 \mathrm{MW} / \mathrm{m}^{2}$. The heat load to the probe can be 'adjusted' by the distance to the separatrix. Knowing the thermomechanical limits allows placing the probe in a 'safe' region.

The design of the NPH has been adapted for the measurements at the mid-plane of AUG vacuum vessel. The installation of NPH at AUG manipulators requires a thicker protective shroud with an outer diameter of $29 \mathrm{~mm}$ that has been constructed specifically for the insertion in AUG (see Figure 2) aiming to provide better shielding against the incident heat flux. The original shroud design [5] had a diameter of $25 \mathrm{~mm}$ and was developed for TCV [7]. Another difference from the original design is that the shroud upper part is made of one piece to achieve a similar expansion of both shroud elements aiming to avoid excessive mechanical stresses and risk of failure. Namely, in the original design, the shroud consists of a small cap on the top of the probe head that is loosely mounted on the remaining part of the shroud [7]. If exposed to the harsh environment of AUG, the cap could detach from the shroud and fall inside a vacuum vessel. This can be avoided by making the upper part of a single piece. The upper part of the shroud (hereinafter referred to as shroud cap) is connected to the lower cylindrical part as shown in the thermal model of the probe in Figure 3.

Due to the port size of the mid-plane manipulator and the high thermal loads at the mid-plane of AUG, an outer cone (see Figure 2) was designed to enable additional protection of the NPH. As seen in Figure 2, only a smaller part of the shroud (approx. $10 \mathrm{~mm}$ ) protruding out of the cone will be directly exposed to SOL. Since the use of similar protective cone is not envisaged in other tokamaks (e.g. TCV [7]), a conservative assumption, without the outer cone protection, is used in the thermal model described in Section 3. Hence, in the model, $50 \mathrm{~mm}$ of the shroud cap is exposed to plasma. 


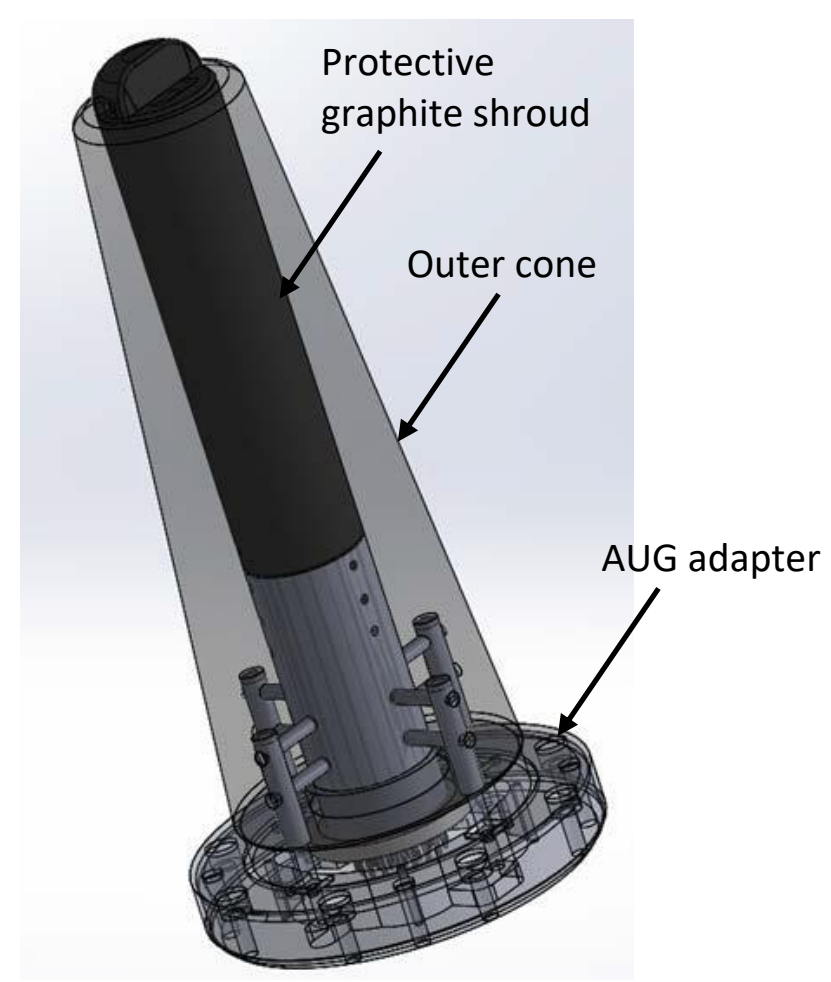

Figure 2: The NPH attached to the adapter at the mid-plane manipulator. Mounting of the additional external graphite cone is also shown.

\subsection{Model definition}

The thermal model of the structural and diagnostic parts of the probe and its protective shroud is somewhat simplified, which means that not all geometrical details are modeled. This significantly reduces the computational effort, but does not affect the thermal behavior of the probe and the shroud. However, geometrical details may become important when studying the structural response of the shroud (see section 4). The main parts in the thermal model of the probe are the following (see Figure 3):

- Protective shroud, made of upper (shroud cap) and lower part (shroud cylinder),

- the probe head, where the diagnostic components are built in,

- the middle part of the probe with the connectors and electrical insulation and

- the probe support made of VESPEL ${ }^{\circledR}$ [8] (named Vespel hereinafter) mounted on the metallic shaft.

The probe head and the connectors are protected by a fine grain graphite shroud that is made of two parts, shroud cap and shroud cylinder. The inner supporting and diagnostic parts in the thermal model are modelled in a way to represent the different materials of the probe. The two inner structural parts, marked in blue color in Figure 3, are made of Vespel. The upper Vespel part is used as a structural support and an electrical insulation. The Vespel is a preferred material for AUG since it practically does not outgas and can be repeatedly heated up to $300^{\circ} \mathrm{C}$ (critical temperature) without losing its thermal or mechanical properties. However, above this critical temperature it may lose its mechanical strength. The cross-section of the probe model with its main parts and materials is presented in Figure 3. The overall modelled length of the probe is $258 \mathrm{~mm}$. 


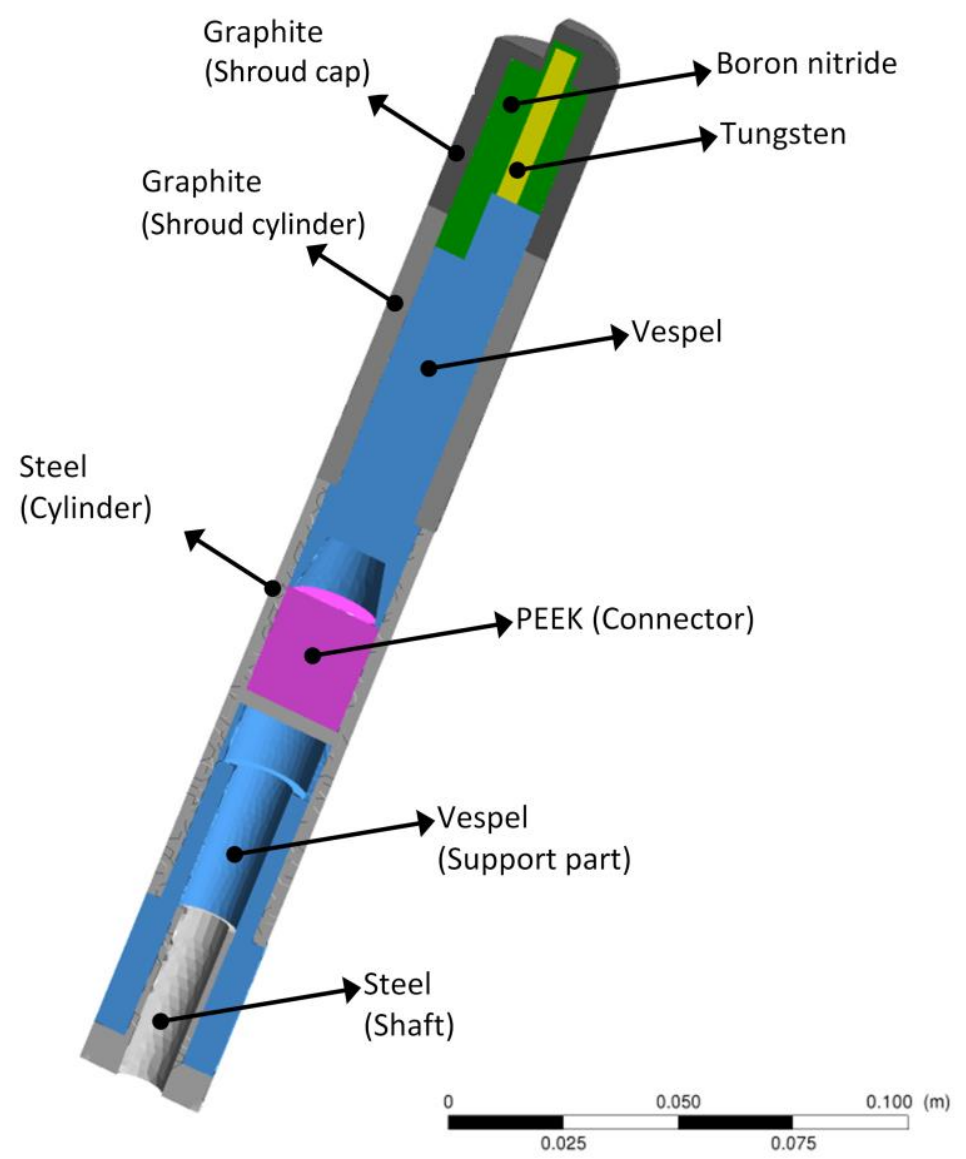

Figure 3: Model of the probe head used for thermal simulations. Different colours represent different materials.

\section{Thermal analysis}

The finite volume ANSYS CFX 18.1 code [9] is used to analyze the thermal behavior of the probe during the pulse sequence inside AUG. The main goal is to predict the thermal response of the probe and identify the critical hot spots to avoid overheating of the shroud and inner parts of the probe.

\subsection{Thermal model}

To set up the consistent thermal model for computational analysis, the geometry was considerably simplified, but in a way to preserve essential thermal characteristics of the probe head components. The thermal model thus consists of 12 solid parts (see Figure 3) made of different materials. Thermal behavior of the probe during successive plasma exposures depends on the heat capacity, thermal conductivity and density of probe materials (see Table 1). Thermal properties of tungsten are modelled as temperature dependent properties [10]. The protective shroud is made of fine grain graphite $\mathrm{R} 6710$ [11][10]. Its thermal conductivity decreases with rising temperature, from $100 \mathrm{~W} / \mathrm{m} \mathrm{K}$ at $20^{\circ} \mathrm{C}$ to $30 \mathrm{~W} / \mathrm{m} \mathrm{K}$ at $2750^{\circ} \mathrm{C} \mathrm{[12].}$ 
Table 1: Material properties of the NPH structural parts

\begin{tabular}{|l|l|l|l|l|l|l|}
\hline & $\begin{array}{l}\text { Graphite } \\
\text { R6710 } \\
{[11],[12]}\end{array}$ & $\begin{array}{l}\text { Vespel } \\
\text { SP1 [8] }]\end{array}$ & $\begin{array}{l}\text { Boron } \\
\text { Nitride } \\
{[13]}\end{array}$ & $\begin{array}{l}\text { PEEK } \\
{[14]}\end{array}$ & $\begin{array}{l}\text { Stainless } \\
\text { Steel }\end{array}$ & Tungsten [10] \\
\hline $\begin{array}{l}\text { Density } \\
{\left[\mathrm{kg} / \mathrm{m}^{3}\right]}\end{array}$ & 1880 & 1430 & 1900 & 1320 & 7854 & 19300 \\
\hline $\begin{array}{l}\text { Spec heat cap. } \\
{[\mathrm{J} / \mathrm{kg} \mathrm{K}]}\end{array}$ & 750 & 1130 & 1610 & 320 & 430 & $\begin{array}{l}129 \text { at } 25^{\circ} \mathrm{C} ; \\
180 \text { at } 2000{ }^{\circ} \mathrm{C}\end{array}$ \\
\hline $\begin{array}{l}\text { Ref. Temp } \\
{\left[{ }^{\circ} \mathrm{C}\right]}\end{array}$ & $\begin{array}{l}\text { Temperature } \\
\text { dependent }\end{array}$ & 25 & 25 & 25 & 25 & $\begin{array}{l}\text { Temperature } \\
\text { dependent }\end{array}$ \\
\hline $\begin{array}{l}\text { Thermal Cond. } \\
{[\mathrm{W} / \mathrm{m} \mathrm{K}]}\end{array}$ & $\begin{array}{l}100 \text { at } 20^{\circ} \mathrm{C} ; \\
30 \text { at } 2750^{\circ} \mathrm{C}\end{array}$ & 0.346 & 30 & 0.25 & 15 & $\begin{array}{l}172 \text { at } 25^{\circ} \mathrm{C} ; \\
100 \text { at } 2000{ }^{\circ} \mathrm{C}\end{array}$ \\
\hline
\end{tabular}

The probe is inserted into the plasma in the radial direction, slightly above the mid-plane of the tokamak. The front part of the shroud cap, in the length of $5 \mathrm{~cm}$, is exposed to the charged plasma particles, which heat up the surface of the shroud cap. In the vacuum environment of the tokamak, the probe and the shroud are cooled by the heat conduction through the solid parts from the shroud cap towards the heat sink at the probe's supporting shaft and by thermal radiation from the outer surface of the graphite shroud towards the cooler surfaces of the vacuum vessel walls. During the probe exposure to the plasma, the following transient heat transfer equation needs to be solved:

$$
\rho c_{p} \frac{d T}{d t}=\nabla \cdot \vec{q}_{\text {heat }}-\nabla \cdot \vec{q}_{c o o l}
$$

where $\vec{q}_{\text {heat }}\left[\mathrm{W} / \mathrm{m}^{2}\right]$ is the incident heat flux due to plasma particles and $\vec{q}_{\text {cool }}\left[\mathrm{W} / \mathrm{m}^{2}\right]$ is the spatial vector of the cooling flux

$$
\vec{q}_{\text {cool }}=\vec{q}_{\text {cond }}+\vec{q}_{\text {rad }}
$$

due to conduction $\vec{q}_{\text {cond }}$ and thermal radiation $\vec{q}_{\text {rad }}$. Variables $\rho$ and $c_{p}$ denote density and specific heat of the material, while $\frac{d T}{d t}$ is the time derivate of the temperature. The heat conduction in the solid domains is calculated as:

$$
\vec{q}_{\text {cond }}=-\lambda \nabla T
$$

where $\nabla T\left[\frac{K}{m}\right]$ is the temperature gradient and $\lambda\left[\frac{\mathrm{W}}{\mathrm{mK}}\right]$ is the thermal conductivity of the material. Thermal radiation exchange can be calculated as follows [15]:

$$
\vec{q}_{\text {rad }}=-\varepsilon \vec{F}_{i j} \sigma\left(T^{4}-T_{o}^{4}\right),
$$

where $\varepsilon$ and $\vec{F}_{i j}$ are the relative emissivity and the view factor between the opposing surfaces and $\sigma$ is the Stefan-Boltzmann constant. The relative emissivity $\varepsilon$ is assumed to be 1 , and $T_{o}$ is the temperature of the surrounding surfaces. For a given geometry configuration (the surface of the shroud inside the vacuum vessel is much smaller than the surface of the vacuum vessel walls) it can be further assumed that $\vec{F}_{i j}$ is equal to 1 .

Contact with the plasma particles is modelled as the incident heat flux on the upper part of the shroud cap. The shroud cap is exposed to the parallel heat flux along the magnetic field lines (perpendicular to the probe axis), which is the highest at the top of the cap and exponentially decays along the probe axis towards the vacuum vessel wall (see Figure 5, left). The incident heat flux can 
be written as:

$$
q_{\text {heat }}=q_{\max } e^{-\frac{\delta}{\lambda_{Q}} \cdot \sin \alpha}
$$

For the conditions in AUG, a maximum heat flux value $q_{\max }$ at the tip of the probe is assumed as $25 \mathrm{MW} / \mathrm{m}^{2}$ and the e-folding length $\lambda_{Q}$ as $3 \mathrm{~cm}$. The coordinate $\delta$ denotes the distance along the probe axis starting from the top of the shroud cap. Due to the rounded shape, the incidence angle of the plasma particles $\alpha$ at the top of the shroud cap is smaller, so the heat flux is also reduced towards the top of the cap. A much smaller heat flux of $0.3 \mathrm{MW} / \mathrm{m}^{2}$ is assumed also in axial direction along the probe axis (perpendicular to the magnetic field lines) to consider thermal radiation from the plasma core, of about $50 \%$ heating power, homogeneously distributed onto the vessel surface of about $20 \mathrm{~m}^{2}$. The vacuum vessel walls are set to a constant temperature of $20^{\circ} \mathrm{C}$. The heat sink for the heat conduction represents the bottom surface of the metal shaft set to a fixed temperature of $20^{\circ} \mathrm{C}$. The initial temperature of the probe at the start of the transient is also set to $20^{\circ} \mathrm{C}$. The triple insertion of the probe into the plasma is modelled as a step function of the incident heat flux $q_{\text {heat }}$. The incident heat flux is turned on during the heating phase (time interval of $0.5 \mathrm{~s}$ ) and off during the cooling phase (time interval of $1 \mathrm{~s}$ ). Heating and cooling phases are manifested by temperature rise or decline, as shown in Figure 6.

The probe components and the protective graphite shroud are meshed by approximately $10^{5}$ prism elements. The meshing of the probe is shown in Figure 4. Conservative heat flux boundary is set at all solid-solid interfaces.
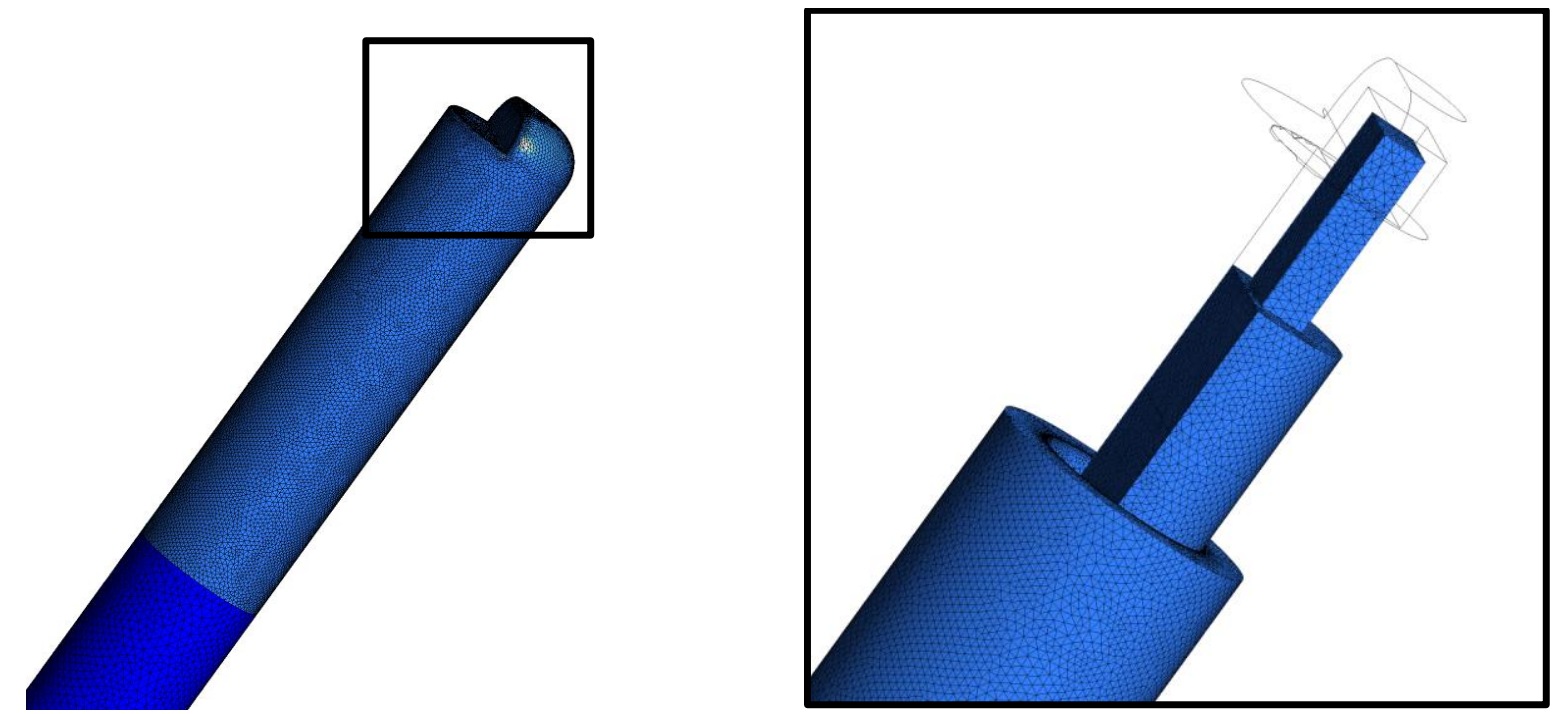

Figure 4: Meshing of the probe shroud with the detail of the meshing of inner probe parts.

\subsection{Simulation of the probe's thermal response}

During one plasma discharge in AUG, usually the probe head is plunged three times into the plasma. The probe exposure time to the edge plasma is $0.5 \mathrm{~s}$ and the delay time between the two plunges is $1 \mathrm{~s}$. The diagnostic part of the probe is shielded by the graphite shroud that is made of two parts (shroud cap and shroud cylinder) as shown in Figure 3. The shroud cap may not be perfectly fitted to the diagnostic part of the probe head and to the shroud cylinder. Hence, some loose contact may exist between the contact surfaces. Concerning the heat transfer the contact surfaces between the shroud cap (graphite), shroud cylinder (graphite) and the inner part of the probe head (Borone nitride and Vespel) can be modelled as a thermal contact resistance. The contact surfaces, where the thermal resistance model has been applied are shown in Figure 5, right. Although the exact value of thermal resistance is not known, its effect can be estimated by 
performing a sensitivity analysis. Three different cases have been investigated:

- Conductive case: A full contact between the shroud cap, diagnostic part of the probe and the shroud cylinder is assumed. There is no thermal resistance between the contact surfaces, a pure heat conduction is modelled.

- Resistance case: It is assumed that the shroud cap is not in full contact with the cylindrical part of the shroud and the diagnostic part. Thermal contact resistance is modelled on these interfaces.

- Isolated case: In this case it is assumed that all surface heat flux from the plasma particles is accumulated solely in the shroud cap and no heat is conducted to the other parts of the probe head. The inner surfaces of the shroud cap facing other probe components are modelled as adiabatic.
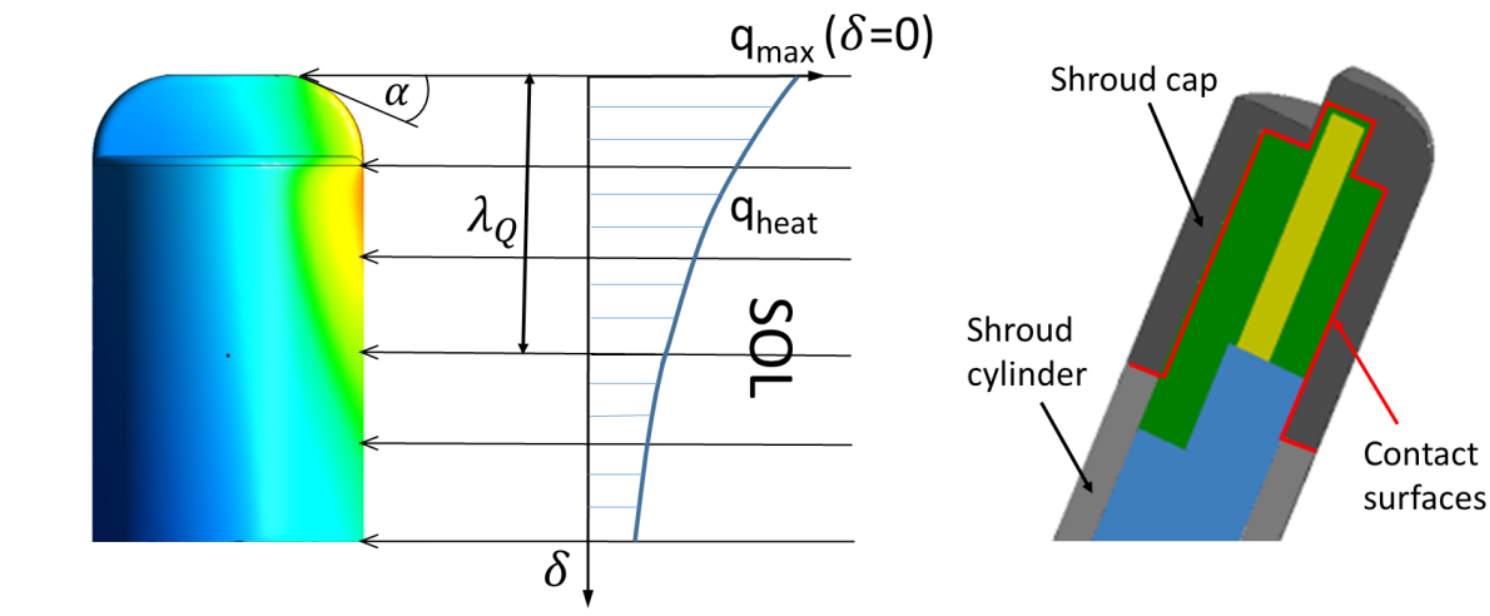

Figure 5: Parallel magnetic field lines and incident heat flux on the shroud cap (left); Contact surfaces in the thermal resistance model (right)

The thermal response of the shroud cap for three different sensitivity cases during three successive probe insertions is shown in Figure 6 - left. The time evolution of the maximum temperature on the shroud cap during three consecutive probe insertions is presented. It can be observed that - expectedly - the highest temperatures are obtained in the "Isolated" case (blue line), where the contact surfaces are modelled as adiabatic surfaces. In this case, all energy is accumulated in the shroud cap, no heat is transferred to the probe head and to the shroud cylinder through the contact surfaces. The shroud cap is cooled only by heat radiation. The maximum temperature achieved after the third pulse (at $3.5 \mathrm{~s}$ ) is $3177^{\circ} \mathrm{C}$, which is still well below the graphite sublimation temperature of $3627^{\circ} \mathrm{C}$ [12]. In the "Conductive" case (green line), the temperatures are lower due to the ideally perfect thermal conduction on the contact surfaces that efficiently transfers the heat from the shroud cap to the neighboring components. The maximum temperature after the third plunge is here $2876^{\circ} \mathrm{C}$.

In reality, the contact between the surfaces is not perfect, but some thermal resistance must be considered. Following reference [16], the thermal resistance between the two contact surfaces made of graphite may range between 10 and $100 \mathrm{~mm}^{2} \mathrm{~K} / \mathrm{W}$. Lower values correspond to a tighter contact and higher values to loosely coupled parts. In this study a conservative value of 100 $\mathrm{mm}^{2} \mathrm{~K} / \mathrm{W}$ is adopted, for the loose contact. The maximum temperature for the "Resistance" case is represented by the red curve in Figure 6 - left. As expected, the red curve falls between the blue and the green one, reaching the maximum temperature of $3095^{\circ} \mathrm{C}$ after the third insertion.

Figure 6 - right shows the thermal response of the inner part of the probe made of Vespel for the first $6 \mathrm{~s}$. The heat is transferred from the shroud to the inner parts of the probe with a certain 
delay. The results for the "Resistance" (red line) and "Conductive" (green line) cases are compared. In the "Conductive" case, the energy from the shroud cap is much easier transferred to the Vespel part due to the lower thermal resistance at the contact interface. In this case, the Vespel part heats up at a faster rate during the heating phase (inserted probe), likewise it also cools down faster when it is pulled out. It continues to rise for about half a second, even during the cool-down phase, where it reaches a maximum temperature of $700^{\circ} \mathrm{C}$. The maximum temperature for the "Resistance" case is lower $\left(670^{\circ} \mathrm{C}\right)$ and it is achieved somewhat later. At approximately $4.5 \mathrm{~s}$, (1 s after the start of the last cooling phase), the maximum Vespel temperature for the "Resistance" case surpasses the temperature of the "Conductive" case, which cools down faster. Maximum temperatures in both cases are much higher than the critical temperature for the Vespel material $\left(300^{\circ} \mathrm{C}\right)$, which could be problematic. However, due to the low thermal conductivity of the Vespel, only a relatively small near-surface region on the top of the Vespel-probe is heated. This is shown in Figure 8c and in Figure 9.
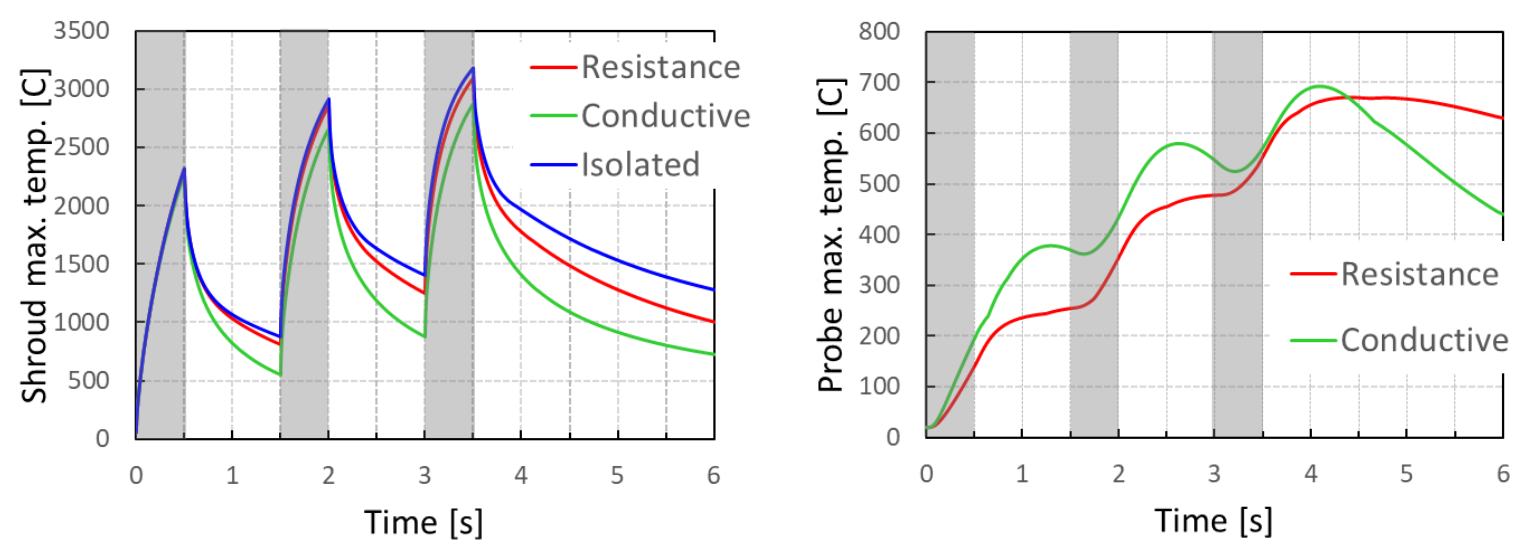

Figure 6: Left: Comparison of maximum temperatures of the shroud cap for three different sensitivity cases during three successive probe insertions. Shaded fields indicate the three heating phases. Right: Comparison of maximum temperatures of the Vespel-probe for the two sensitivity cases during three successive probe insertions

The lower supporting part made of Vespel is more important from the point of view of structural integrity. Thermal responses of the shroud cap and of the two Vespel parts inside the probe (Vespel-probe and Vespel-support) for the "Resistance" case are presented in Figure 7. Graphs on the left show the evolution of maximum temperatures for the first $50 \mathrm{~s}$ and the graphs on right represent the maximum temperatures during a longer cool-down phase of $20 \mathrm{~min}$. Due to the slow heat conduction through the probe components, the Vespel-support part (blue line) does not heat up during the first $50 \mathrm{~s}$. The maximum temperature of the Vespel-probe (green line) persists above the limiting value of $300^{\circ} \mathrm{C}$ for $38 \mathrm{~s}$, then it cools down rather slowly, after 20 min $(1200 \mathrm{~s})$ its temperature is still $63^{\circ} \mathrm{C}$. The maximum temperature of the Vespel-support rises to $42^{\circ} \mathrm{C}$ during that time, which is well below the limiting value. During the cool-down phase the maximum temperature of the shroud cap (red line) slowly approaches the Vespel-probe temperature and continues below its value from about $100 \mathrm{~s}$ onwards to reach $60^{\circ} \mathrm{C}$ after $20 \mathrm{~min}$.

Temperature distributions in the probe at $3.5 \mathrm{~s}$, just at the end of the third insertion, are shown in Figure 8. The highest temperature is concentrated on the surface of the shroud cap slightly below its top (Figure 8a). The temperature over the half-cut of the shroud, the tungsten part and the Vespel-probe is shown in Figure 8b. Temperature distribution on the surface of the Vespel part in the probe head is presented in Figure 8c. It can be seen that the concentration of high temperature is limited to a small surface region on the top of the Vespel-probe. Figure $8 \mathrm{~d}$ presents the temperature distribution on the half-cut of the inner part of the probe head made of boron nitride (BN) just below the shroud cap. 
Figure 9 shows the regions with temperature values above $300^{\circ} \mathrm{C}$ for the Vespel-probe at different time instances. Due to the low thermal conductivity of the Vespel material (see Table 1) the heat is mainly dissipated over the probe surface and does not penetrate deep into the body structure. The overheating of the Vespel on top of the probe may be avoided by increasing the gap between Vespel and the Shroud cap in the upper part.

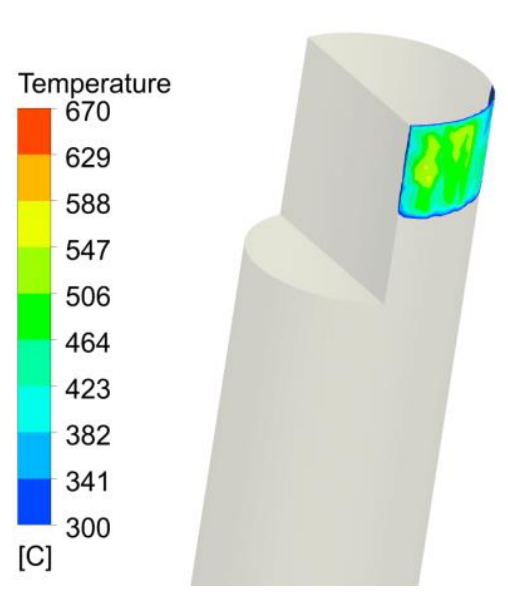

$3.5 \mathrm{~s}$

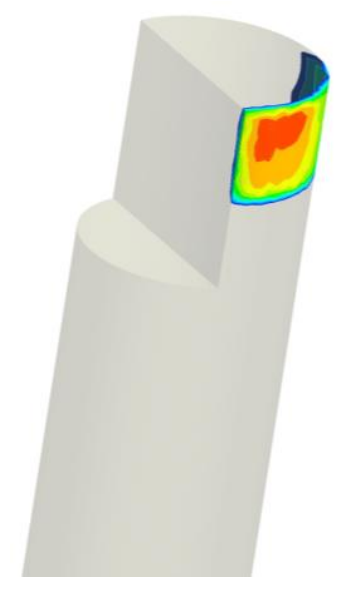

$5.2 \mathrm{~s}$

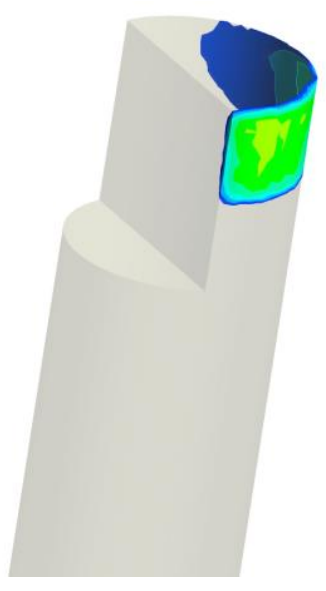

$8.3 \mathrm{~s}$

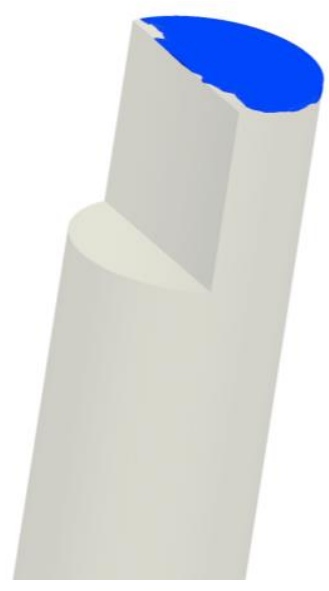

$28.3 \mathrm{~s}$

Figure 9: Temperature contours of the Vespel-Probe at different time instances: regions of temperatures above $300^{\circ} \mathrm{C}$ are shown

\section{Structural analysis of shroud cap}

This section describes the structural model and analyses of the shroud cap performed with the finite element (FE) code ABAQUS [17]. With the aim to study the stresses in the shroud cap during the selected transients, the time-dependent temperatures obtained in the thermal analyses are employed in this section as thermal boundary conditions for the structural model.

\subsection{Structural model and boundary conditions}

The geometrical details omitted in the heat transfer model, such as the holes for the pins and the round edges, are expected to affect the mechanical response of the shroud cap. Therefore, the detailed geometry shown in Figure 10 is used in the structural model. The fine grain graphite Grade R6710 is assumed with constant material properties [11], which include the elastic Young's modulus of $13.5 \mathrm{GPa}$, the thermal expansion coefficient of $4.7 \times 10^{-6} \mathrm{~K}^{-1}$ and Poisson's ratio equal to 0.2 .

Figure 10 also depicts the displacement boundary conditions applied on the shroud cap. These restrict the vertical displacement (in y-direction, $U_{y}=0$ ) of the lower surface and, additionally, four outer points on the lower surface, two located along the $\mathrm{x}$-axis $\left(\mathrm{U}_{\mathrm{z}}=0\right)$ and two along the $\mathrm{z}$-axis $\left(\mathrm{U}_{\mathrm{x}}=0\right)$, prevent horizontal displacements in the $\mathrm{z}$ and $\mathrm{x}$ directions, respectively. These boundary conditions avoid the free-body movement and rotation of the shroud cap without affecting its deformation due to the non-homogenous temperature distribution. The model mesh shown in Figure 11 is composed of approximately $3.88 \times 10^{5}$ tetrahedral quadratic elements. The mesh is denser on the upper part of the cap where the geometrical details are located. The time-dependent temperatures of the shroud cap obtained in the thermal analyses are mapped onto the FE meshes using analytical mapped field interpolation in ABAQUS. The mapped temperatures are then used as thermal boundary conditions in the structural analyses to study the thermal deformations and stresses. Thus, for each of the selected transients, a static analysis is performed for each time step 
with the mapped temperatures from thermal analysis, which correspond to variable time steps of about $0.1 \mathrm{~s}$ for the transient time below $4.5 \mathrm{~s}, 1 \mathrm{~s}$ for the transient time between $4.5 \mathrm{~s}$ and $13 \mathrm{~s}$, and to the time step of $10 \mathrm{~s}$ for the time period from $13 \mathrm{~s}$ till the end of transient (1200 s).

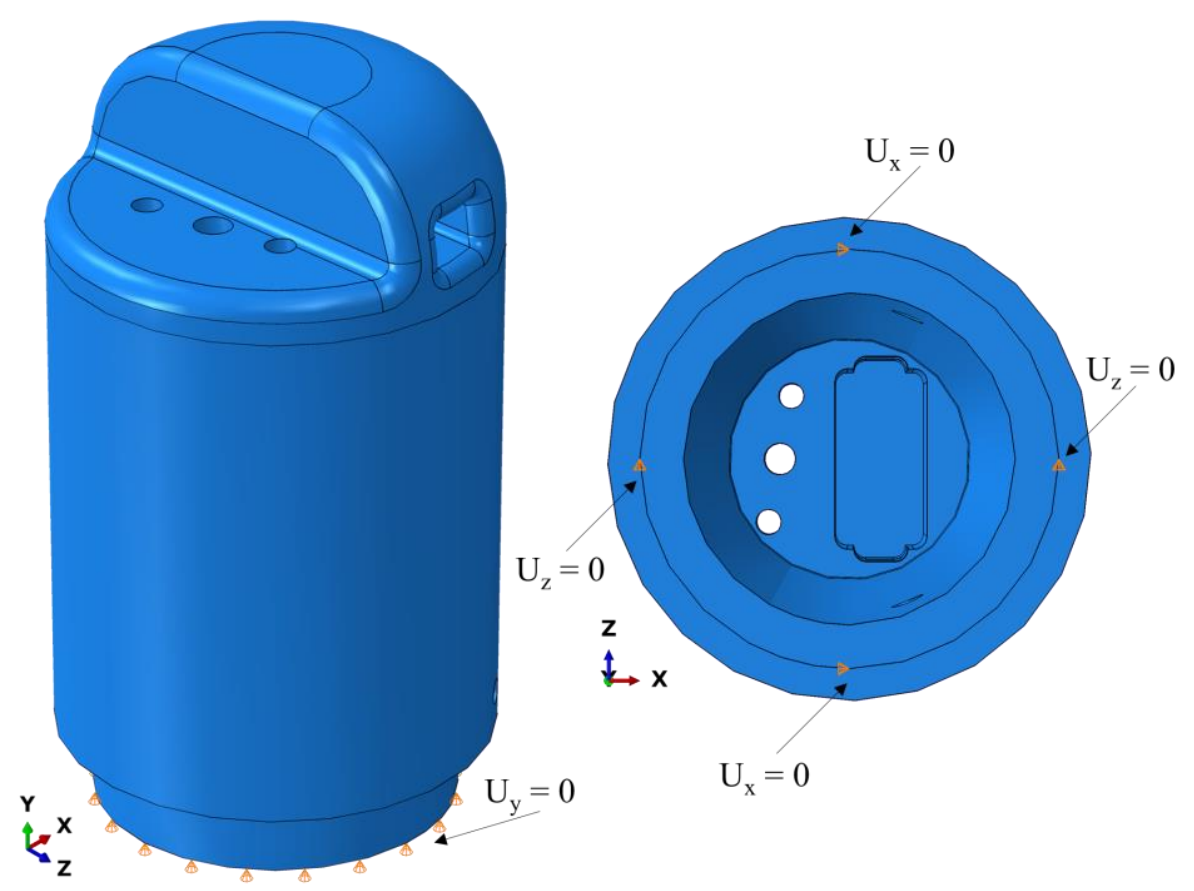

Figure 10. Shroud cap geometry in the structural model with displacement boundary conditions applied on the lower surface
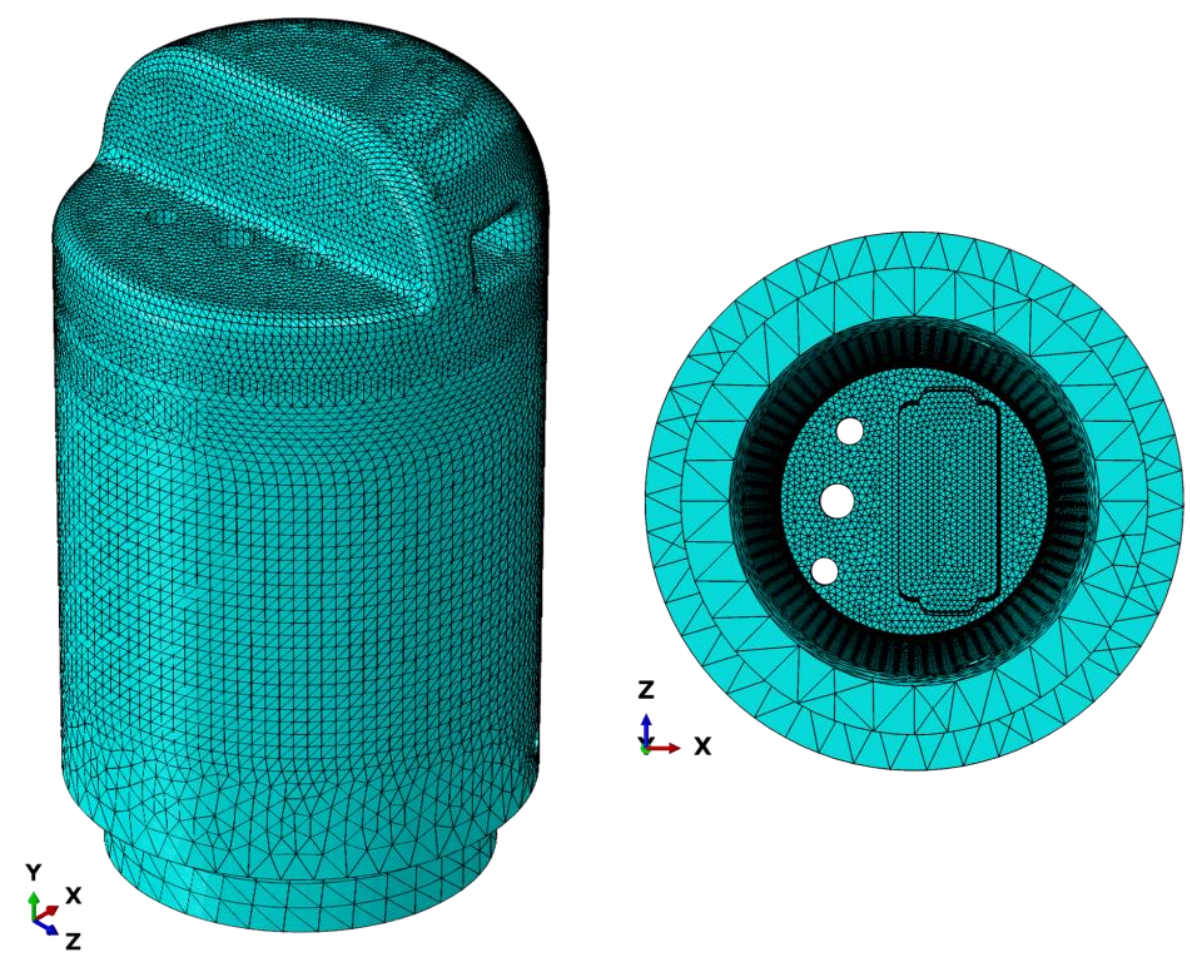

Figure 11. Finite element meshes of the structural model composed of tetrahedral quadratic elements 


\subsection{Time-dependent analysis of thermal stresses in the shroud cap}

As the shroud cap heats up and cools down during the transient, its non-uniform temperature distribution translates to a non-homogenous deformation. This is presented in Figure 12 by the temperature distribution successfully mapped onto the FE mesh, and the distribution of the displacement magnitude. Both distributions correspond to the thermal resistance transient after the third insertion into the plasma, i.e. at time $3.5 \mathrm{~s}$. As shown in Figure 12, the maximum displacement of about $0.38 \mathrm{~mm}$ can be expected at the upper surface of the cap, above the side hole for the RFAs where the maximum temperature is obtained. The predicted displacements are not expected to present any challenges to the overall probe performance.
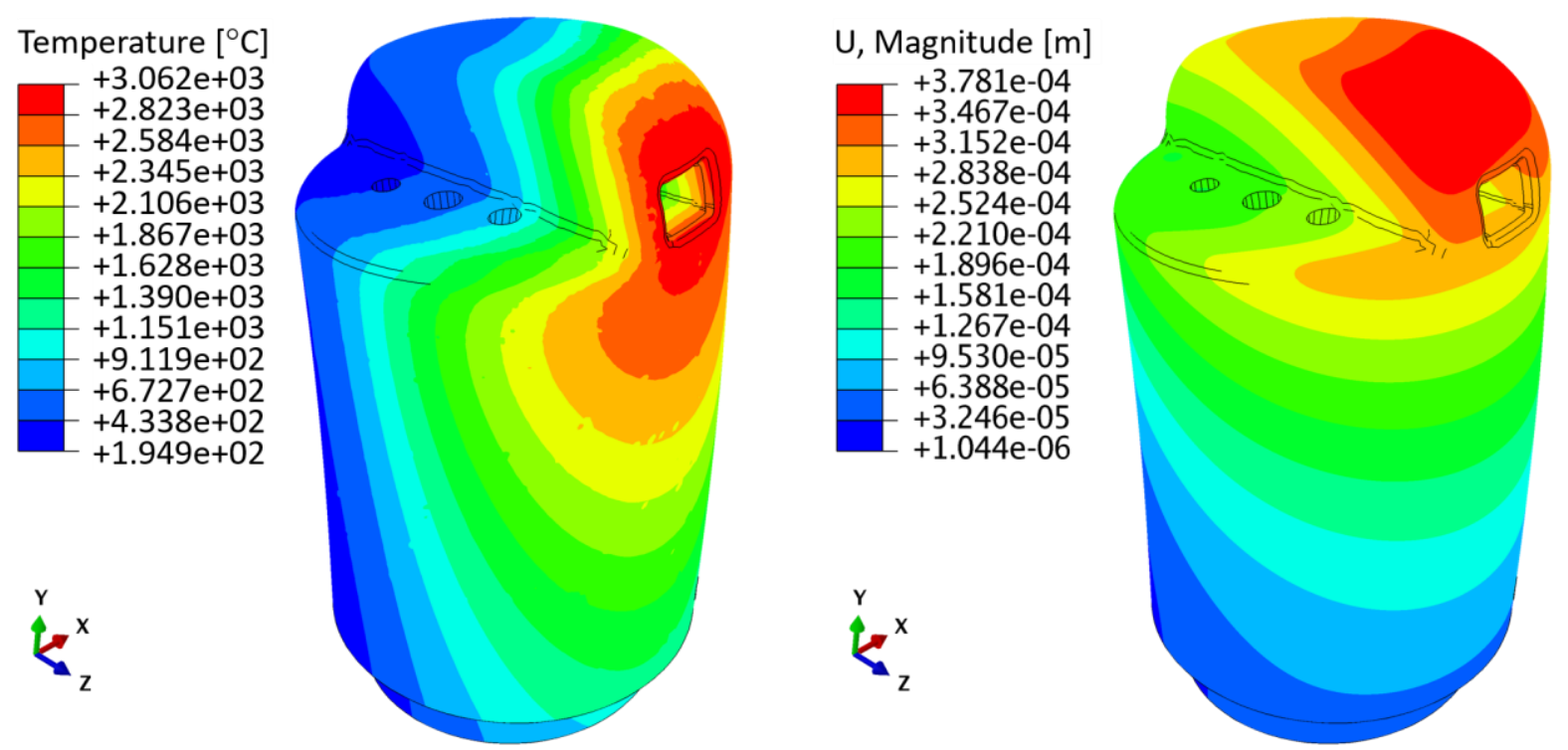

Figure 12. Shroud cap temperature (left) and displacements magnitude (right) after the third insertion, at time $3.5 \mathrm{~s}$, for the thermal resistance transient. Note scale the factor of 14.5

The non-uniform temperature typically also implies internal constraints and, thus, thermal stresses arising in the shroud cap. This is a consequence of neighbouring sections at different temperatures precluding the free deformations of the adjacent ones. Also at $3.5 \mathrm{~s}$ into the thermal resistance transient, Figure 13 shows the maximum and minimum principal stress distributions. These represent, respectively, the maximum tensile (positive sign) and maximum compressive (negative sign) stresses in the shroud cap. A maximum tensile stress of about $90 \mathrm{MPa}$ is observed at one of the probe holes (Point A) as well as at the inner edge (Point B). A maximum compressive stress of about $123 \mathrm{MPa}$ is obtained at the edge of the side hole for the RFAs (Point C). These stresses are rather localized and induced by the deformations arising from the temperature distributions in combination with the geometrical features of the shroud cap.

The stress histories for the three points A, B and C and for the three transients can be seen in Figure 14 (for the location of the points see Figure 13). While the highest maximum principal stress at Point $\mathrm{A}$ is observed for the thermal resistance transient, the stress levels for the other two transients (isolated and conductive) are also seen to follow very closely. In absolute terms, the highest stresses at Points B and C are obtained for the fully conductive case. 


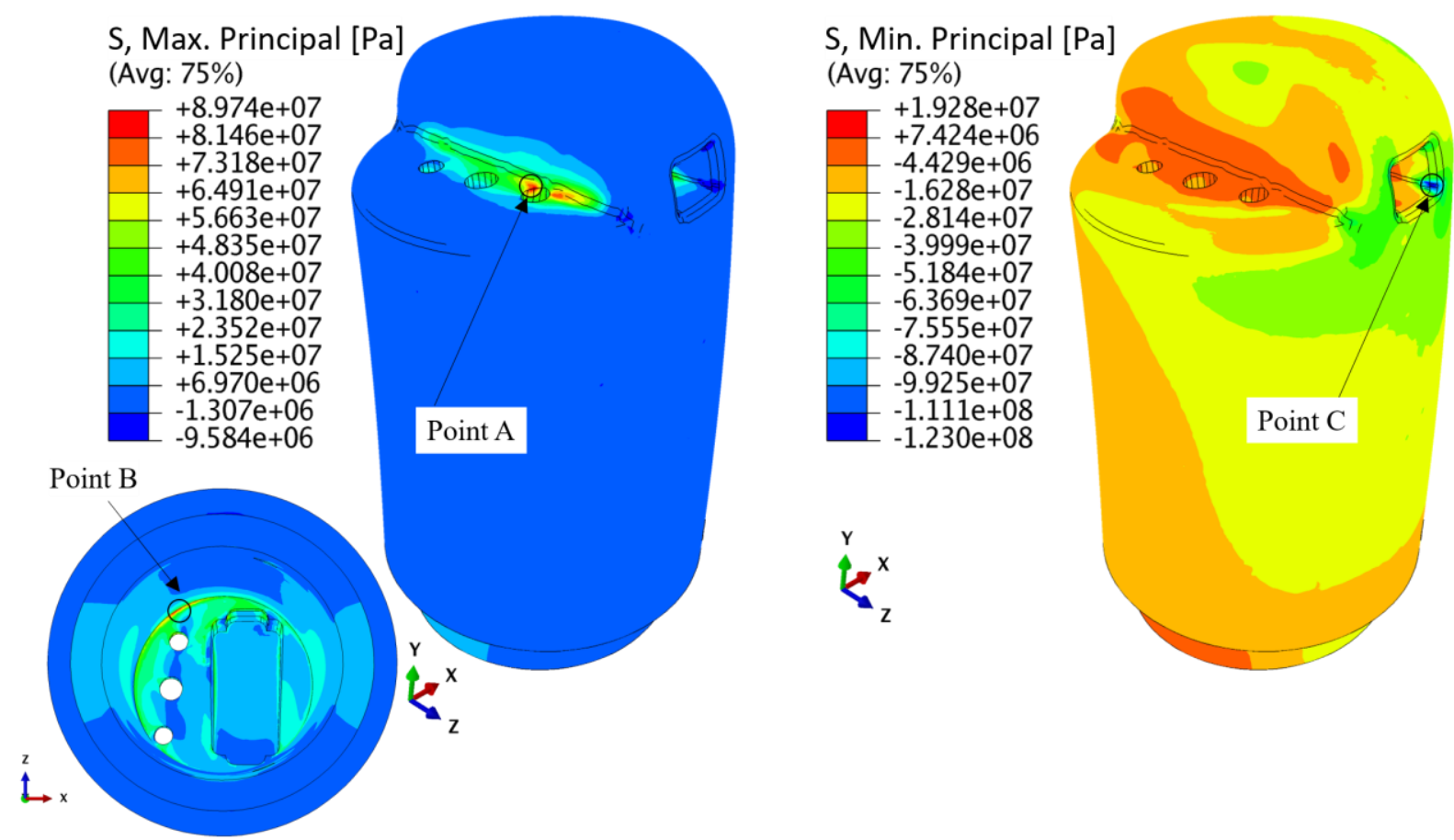

Figure 13. Maximum (left) and minimum (right) principal stress distribution in the shroud cap after the third insertion, at $3.5 \mathrm{~s}$, for the thermal resistance transient. Note scale the factor of 14.5
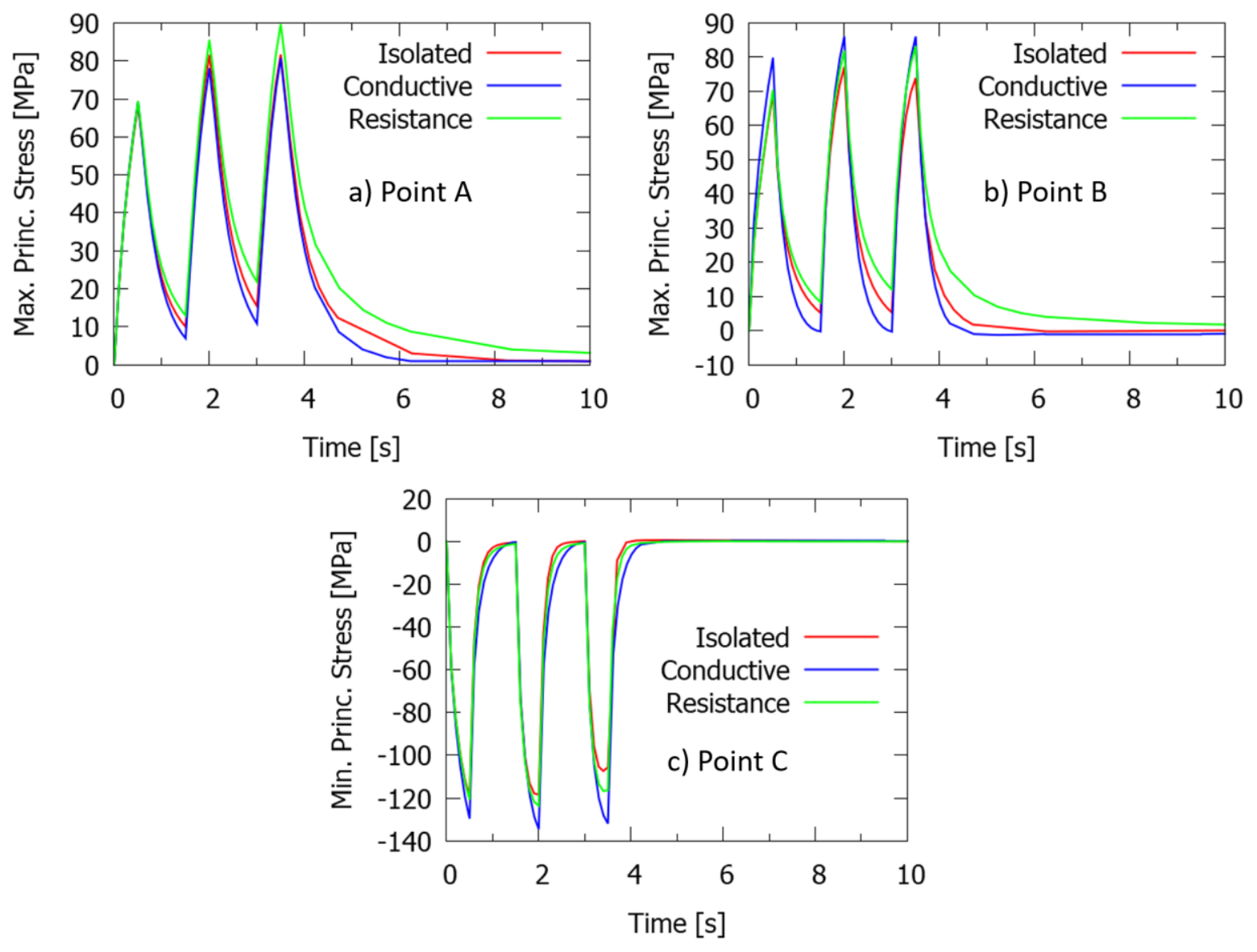

Figure 14. Maximum principal stress histories at the probe hole (Point A) and at the inner edge (Point B) and minimum principal stress history at the side hole (Point C) for the 3 transients. See Figure 13 for the exact location of the points. 
The available data for material strength of the graphite Grade R6710 is rather scarce. For the sake of reference, the analysis of the shroud cap structural integrity can be attempted with the known flexural strength of $85 \mathrm{MPa}$ and the compressive strength of $170 \mathrm{MPa}$ at room temperature [11], compared against the maximum and minimum principal stresses obtained in the simulations. While the compressive strength seem to be well above the minimum principal stress of $\sim 135 \mathrm{MPa}$ (conductive transient), the flexural strength and the maximum principal stress of $90 \mathrm{MPa}$ are very close to each other. However, it is known that the strengths of graphite increase with temperature, e.g. some references [12] indicate that the strengths may double their value at temperatures of about $2700 \mathrm{~K}\left(\sim 2427^{\circ} \mathrm{C}\right)$ and beyond this temperature the strengths will start to decrease again. Thus, the local stresses at the most loaded locations and the temperatures at those locations will dictate the structural integrity of the shroud cap.
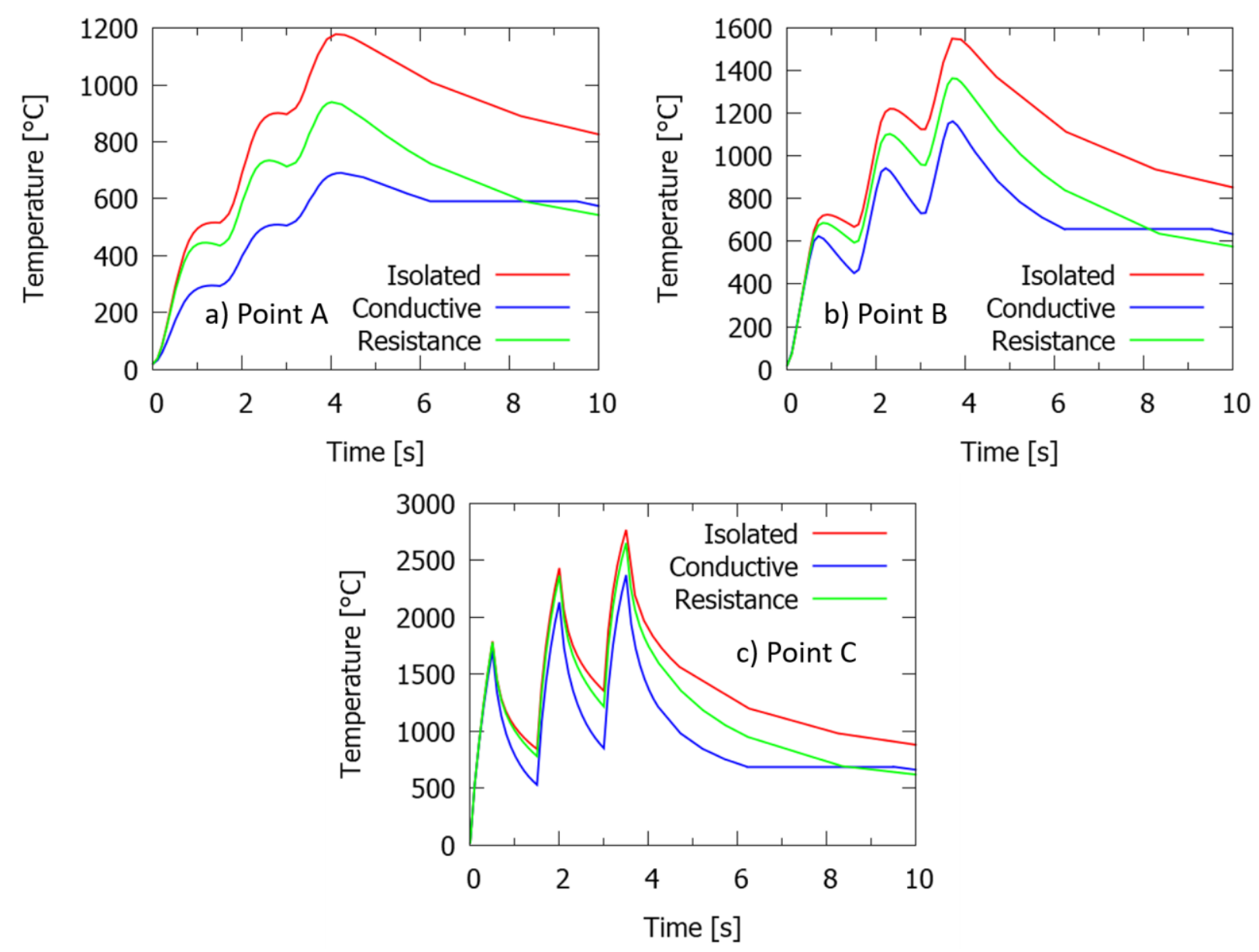

Figure 15. Temperatures at the probe hole (Point A), at the inner edge (Point B) and the side hole (Point $C$ ) for the 3 cases. See Figure 13 for the exact location of the points

The time-dependent temperatures for the points of interest and for the 3 transients are presented in Figure 15 in the same form as the time-dependent stresses in Figure 14. Only the temperature of Point $\mathrm{C}$ goes above $2427^{\circ} \mathrm{C}$ during the second and third insertions for the isolated and resistance transients. For the times when the shroud is inserted into the plasma, the relevant stresses for the 3 locations of interest are synthesized in Table 2 for the 3 transients. Unfortunately, the exact data for the Grade R6710 is not available; thus, a precise integrity analysis cannot be performed at this point. However, and based on the general graphite properties described above, 
the maximum principal stresses at Point A and B are achieved when the material is above $800 \mathrm{~K}$, which approximately corresponds to an increase of about $10 \%$ on the material strength [12]. Thus, the increase of material strength at high temperatures may be the actual margin to the safe integrity of the cap at these two locations. At Point $\mathrm{C}$, the compressive stresses are expected to remain below the increased compressive strength at high temperatures, regardless that the temperature at this location goes above the reference $2427^{\circ} \mathrm{C}$. Thus this location does not represent a challenge to the cap integrity. The cyclic operation of the shroud due to repetitive insertion into the plasma may also indicate a possible failure due to fatigue damage. Therefore, it may be worth pointing out here that, if the fatigue strength was available, a conservative fatigue analysis could be also performed in the future using the stress maxima provided in Table 2 as stress amplitudes, in order to obtain the allowable number of cycles to failure, i.e. number of shroud insertions into the plasma.

Table 2. Synthesis of temperatures and stresses at the points of interest for the 3 transient cases

\begin{tabular}{|c|c|c|c|c|c|c|}
\hline & \multicolumn{2}{|c|}{ Resistance } & \multicolumn{2}{|c|}{ Conductive } & \multicolumn{2}{|c|}{ Isolated } \\
\hline \multicolumn{7}{|l|}{ Point A } \\
\hline Time [s] & $\mathrm{T}\left[{ }^{\circ} \mathrm{C}\right]$ & Max.P.S. $[\mathrm{MPa}]$ & $\mathrm{T}\left[{ }^{\circ} \mathrm{C}\right]$ & Max.P.S. $[\mathrm{MPa}]$ & $\mathrm{T}\left[{ }^{\circ} \mathrm{C}\right]$ & Max.P.S. $[\mathrm{MPa}]$ \\
\hline 0.5 & 277.6 & 69.4 & 173.3 & 69.3 & 294.0 & 68.5 \\
\hline 2.0 & 588.3 & 85.6 & 399.1 & 78.1 & 692.5 & 81.6 \\
\hline 3.5 & 826.3 & 89.7 & 592.1 & 80.8 & 1027.7 & 81.7 \\
\hline \multicolumn{7}{|l|}{ Point B } \\
\hline Time [s] & $\mathrm{T}\left[{ }^{\circ} \mathrm{C}\right]$ & Max.P.S. [MPa] & $\mathrm{T}\left[{ }^{\circ} \mathrm{C}\right]$ & Max.P.S. $[\mathrm{MPa}]$ & $\mathrm{T}\left[{ }^{\circ} \mathrm{C}\right]$ & Max.P.S. $[\mathrm{MPa}]$ \\
\hline 0.5 & 535.4 & 70.5 & 516.8 & 79.9 & 547.8 & 69.2 \\
\hline 2.0 & 972.1 & 82.0 & 842.1 & 86.1 & 1064.8 & 77.2 \\
\hline 3.5 & 1260.4 & 83.3 & 1073.0 & 86.0 & 1437.4 & 73.9 \\
\hline \multicolumn{7}{|l|}{ Point $\mathrm{C}$} \\
\hline Time [s] & $\mathrm{T}\left[{ }^{\circ} \mathrm{C}\right]$ & Min.P.S. [MPa] & $\mathrm{T}\left[{ }^{\circ} \mathrm{C}\right]$ & Min.P.S. [MPa] & $\mathrm{T}\left[{ }^{\circ} \mathrm{C}\right]$ & Min.P.S. [MPa] \\
\hline 0.5 & 1782.6 & -120.8 & 1706.2 & -129.7 & 1788.8 & -119.3 \\
\hline 2.0 & 2365.6 & -123.6 & 2131.9 & -134.6 & 2433.1 & -118.4 \\
\hline 3.5 & 2653.2 & -116.4 & 2371.5 & -132.0 & 2769.4 & -105.7 \\
\hline
\end{tabular}

\section{Conclusions}

The behaviour of the new probe head during the 3 successive plunges of $0.5 \mathrm{~s}$ into AUG plasma, separated by $1 \mathrm{~s}$ of delay time has been studied numerically. Thermal and mechanical responses of the most critical parts of the probe have been analysed. The study shows that the probe shroud and its internal components are not critically overheated, when exposed to AUG plasmas equal to or lower than $25 \mathrm{MW} / \mathrm{m}^{2}$. The inner part of the probe made of Vespel may represent a potential threat to the probe integrity, since its critical temperature of $300^{\circ} \mathrm{C}$ has been exceed substantially. However, the results show that the high temperature region is limited to a very localized surface region on the top of the Vespel part. Therefore it is not expected that the structure integrity should be threatened. Nevertheless, to avoid overheating of the Vespel on top of the probe, it is recommended to increase the gap between Vespel and the shroud in the upper part. The temperature of the Vespel supporting part stabilizes at $42^{\circ} \mathrm{C}$ after 20 minutes of cool-down phase and always stays well below the critical temperature.

To assess the potential pollution of the vacuum vessel, the main focus in the analysis is given to the thermal response of the protective shroud. The important source of uncertainty in prediction of its thermal behaviour represents the unknown thermal contact between the protective shroud and 
inner parts of the probe. This has been properly considered by three different thermal contact models for the shroud cap. Even the most conservative case, with the fully isolated shroud cap has shown that the protective shroud is able to withstand the repeated plasma exposure. In all modelled cases the maximum temperatures stay well below the graphite sublimation temperature of $3627^{\circ} \mathrm{C}$.

The time-dependent temperatures obtained in the heat transfer analyses have been employed in the structural analyses to study the deformations and stresses in the shroud cap during the selected transients. After successful mapping of the shroud cap temperatures onto the FE mesh, the results indicate that there are two locations, namely one of the probe holes and the inner edge, which may reach tensile stresses near the flexural strength of the graphite. However, based on the known increase of the graphite strengths with temperature, there seems to be sufficient margin for the safe shroud integrity. Due to the clear cycling operation of the shroud due to repetitive insertions into the plasma, a future fatigue analysis will be required once the fatigue strength becomes available.

\section{ACKNOWLEDGEMENTS}

This work has been carried out within the framework of the EUROfusion Consortium and has received funding from the Euratom research and training programme 2014 - 2018 and 2019 2020 under grant agreement No 633053. The views and opinions expressed herein do not necessarily reflect those of the European Commission.

The financial support provided by the Slovenian Research Agency through the core research programs P2-0405 and P2-0026 is gratefully acknowledged. Some partial funding is received also from the projects ARRS-FWF (BI-AT/18-19-020) and P2-0073. This work was also supported by the Friedrich Schiedel Foundation for Energy Technology, the Commission for the Coordination of Nuclear Fusion Research in Austria of the Austrian Academy of Sciences (KKKÖ No. MG 2017-5), the Tyrolean Science Funds (TWF under No. UNI-0404/2063) and the bilateral ScientificTechnical Collaboration project (WTZ SI 09/2016) of the Austrian Exchange Service (OeAD).

\section{REFERENCES}

[1] C. Ionita-Schrittwieser, B. S. Schneider, O. Vasilovici, R. Schrittwieser, A. Herrmann, R. Stärz "Developing adaptors to facilitate interchangeable probes between MST devices", MST2- 014.1-T002-D001, Interim Report of MST2, OeAW-IEPPG, DTU, JSI, ENEARFX, IPP-Garching, TCV, Jan 2019.

[2] A. Herrmann, O. Gruber, Chapter 1: ASDEX Upgrade - Introduction and Overview, Fusion Sci. Techn. 44 (2003), 569-577.

[3] F. Hofmann et al., Creation and control of variably shaped plasmas in TCV, Plasma Phys. Contr. Fusion 36 (1994), B277-B287.

[4] D. Clery, The new shape of fusion, Science 348 (2015), 854-856.

[5] C. Ionita, B.S. Schneider, S. Costea, O. Vasilovici, J. Kovačič, T. Gyergyek, V. Naulin, J.J. Rasmussen, N. Vianello, M. Spolaore, R. Stärz, R. Schrittwieser, "Plasma potential probes for hot plasmas", Europ. Phys. J. D 73 (2019), 73 (16pp) (https://doi.org/10.1140/epjd/e2019-90514-5)

[6] B.S. Schneider, N. Vianello, M. Spolaore, V. Naulin, J.J. Rasmussen, R. Stärz, J. Kovačič, T. Gyergyek, S. Costea, C. Ionita, R. Schrittwieser, Tsv. K. Popov, "Multi-diagnostic probe head for near-wall electric and magnetic measurements in medium-size tokamaks", $44^{\text {th }}$ 
EPS Conf. Plasma Phys. (Belfast, Northern Ireland, UK, 26-30 June 2017; 29 June 2017); poster, P4.105 (http://ocs.ciemat.es/EPS2017ABS/pdf/P4.105.pdf).

[7] B.Končar et al., Analysis of Thermal Response of New Diagnostic Probe in TCV, Fusion Eng. Des., 2020.

[8] Dupont Vespel@ SP-1 Polyimide datasheet, 2014.

[9] ANSYS CFX documentation, 18.1

[10] ITER Material Properties Handbook, 2001.

[11] SGL CARBON GROUP, RINGSDORF® Specialty Graphite, Grade R6710 datasheet.

[12] SGL CARBON GROUP, SGL Carbon's Graphite Specialties, Materials and Products for Continuous Casting Technology.

[13] Boron Nitride, BN Ceramic Properties, 2013, https://www.accuratus.com/boron.html

[14] Ketron® 1000 PEEK, Product Data Sheet, 2014

[15] M. F. Modest, Radiative heat transfer, McGraw-Hill, New York, 1993.

[16] E. E. Marotta, S. J. Mazzuca. J. Norley. Thermal Joint Conductance for Flexible Graphite Materials: Analytical and Experimental Study, IEEE Transactions on Components and Packaging Technologies, 28, No.1 (2005) 102-110.

[17] ABAQUS. Dassault Systèmes Simulia Corp, Providence, RI, USA; 2017. 